\title{
RETRACTED ARTICLE: Clean process for the production of renewable BTEX
}

\author{
Swapnil L. Fegade ${ }^{1}$ (D)
}

Received: 20 June 2016/ Accepted: 17 September 2016/Published online: 1 October 2016

(c) Springer-Verlag Berlin Heidelberg 2016

This article has been retracted by the Editor-in-Chief because the author did not have permission to publish the data. The work presented in this paper was performed by the author as part of his graduate studies at the University of North Dakota, and several other researchers were very closely involved in the conception, execution, and analysis of the work. The paper was submitted to us without the consent of the advisers or collaborators. The author apologizes for his negligence.

Electronic supplementary material The online version of this article (doi:10.1007/s10098-016-1283-z) contains supplementary material, which is available to authorized users.

Swapnil L. Fegade

swapnil.und@gmail.com

1 University of North Dakota, 290 Centennial Drive Stop 8178,

Grand Forks, ND 58202, USA 